\title{
Coronavirus, Deafness and the Use of Different Signs of the Area in Health during a Period of Pandemic Time: Is That the Best Option to Do?
}

\author{
Gildete Amorim¹, Alex Sandro Lins Ramos ${ }^{1,2}$, Gláucio de Castro Junior ${ }^{3}$, \\ Luciana de Souza Afonso' ${ }^{2}$, Helena Carla Castro1,2,4* \\ ${ }^{1}$ Post-Graduation Programs in Science and Biotechnology, PPBI, UFF, Niterói, Brazil \\ ${ }^{2}$ Post-Graduation Program in Teaching of Biosciences and Health, PGEBS, Fiocruz, Rio de Janeiro, Brazil \\ ${ }^{3}$ Department of Linguistic, Portuguese and Classic Languages_LIP of Institute of Letters-IL, UnB, Brasília, Brazil \\ ${ }^{4}$ Post-Graduation Program in Sciences, Technology and Inclusion, PGCTIn and CMPDI, UFF, Rio de Janeiro, Brazil \\ Email: ^hcastrorangel@yahoo.com.br, ^hcastro@id.uff.br
}

How to cite this paper: Amorim, G., Ramos, A. S. L., de Castro Junior, G., de Souza Afonso, L., \& Castro, H. C. (2020). Coronavirus, Deafness and the Use of Different Signs of the Area in Health during a Period of Pandemic Time: Is That the Best Option to Do? Creative Education, 11, 573-580. https://doi.org/10.4236/ce.2020.114042

Received: February 28, 2020

Accepted: April 17, 2020

Published: April 20, 2020

Copyright $\odot 2020$ by author(s) and Scientific Research Publishing Inc. This work is licensed under the Creative Commons Attribution International License (CC BY 4.0).

http://creativecommons.org/licenses/by/4.0/

\begin{abstract}
The World Health Organization has decreed the new Coronavirus as a worldwide threat. This new virus causes COVID-19 with a threatening mortality rate and a high risk of contamination. Initially, the outbreaks began in China, then Iran, Italy, South Korea and now are present in all continents. Since only attitudes such as Hand-washing and quarantine can help in controlling this epidemic disease, these pieces of information need to be clearly spread on the whole society, including minorities such as the deaf community. Therefore, in this work, we briefly compared three signs about this virus currently in use in Brazil by the deaf community, focused on some linguistics characteristics (e.g. meaning ad concepts). Our results showed that it is important for taking care of the information delivery for the whole society including minorities such as the deaf community to avoid possible linguistic impairments about serious threats such as coronavirus.
\end{abstract}

\section{Keywords}

Coronavirus, Deaf, Sign Language, Health

\section{Introduction}

The crisis caused by the emergence of the new coronavirus, and the COVID_19 highlighted the global fear involving not only health issues but also the world economic order. In order to avoid a high number of deaths, the World Health 
Organization (WHO) and other important organizations established parameters and protocols internationally that should be followed by all people in all countries, despite their economical level or access to simple things such as water and soap (WHO, 2020; CDC, 2020).

However, our society is composed of many groups of people, including linguistic minorities such as deaf community (e.g. Sign Language) ( $\mathrm{Du}, 2020)$ which depends on linguistic adapted/translated materials (e.g. press and online) for accessing preventive and protective information and/or guidance (e.g. hand-washing and protection from coughing and human fluids). The disadvantages brought by the lack of information in sign language about coronavirus to the deaf community may compromise not only their own health but also their community including children, family, and friends (Castro et al., 2020).

As new terms, COVID-19 and coronavirus needed signs to be created and used in the presentation of this virus and disease as a pandemic situation of high dead risk to deaf (Castro et al., 2020). During situations involving high health risks such as the coronavirus pandemic, WHO together with Word Federation of Deaf-WFD (https://wfdeaf.org) should be the ones that standardize a sign for using during this situation, giving full accessibility to all deaf people worldwide simultaneously. However, currently, Brazil has more than three signs for coronavirus, whereas hearing people has only one word (written and spoken) to be informed about it (Castro et al., 2020).

Sign languages are considered natural languages and, consequently, share a series of characteristics that give them a specific character and distinguish them from other communication systems, for example, unlimited productivity (unlimited number of messages on an unlimited number of topics); creativity (independent of stimulus); the multiplicity of functions (communicative, social and cognitive functions that expressing thoughts), among others. Sign languages are, therefore, considered by linguistics as a legitimate linguistic system that met all the linguistic criteria of a genuine language, in the lexicon, in the syntax and in the capacity to generate an infinite number of sentences (Quadros, 2019; Prietch et al., 2019; Albres, 2012). However, sign languages such as Brazilian Sign language-Libras, which are so young and dynamic, need to be studied and evaluated continuously to assure the accessibility of the deaf community to the whole information that hearing people have access easily by their written and oral language formats (Prietch et al., 2019; Albres, 2012).

In this work, we briefly analyze the three Brazilian signs currently used for coronavirus in a coercive social way in different situations, also comparing linguistic variation, in order to discuss the possibility of linguistic damage and health risks for the deaf community and the entire near and inner society.

\section{Methods}

\section{Data collection instruments and Sign Evaluation}

Many signs of the Brazilian Deaf Community about Coronavirus are still not present in any of the dictionaries and glossaries disposable as still is a new sub- 
ject for all. Therefore we collected the signs from 20 videos of deaf and sign language interpreters and provisional archived record digitally including TV INES from Roquete Pinto in association to Instituto Nacional de Educação de Surdos (INES), which is a Brazilian TV channel with $100 \%$ accessibility to Brazilian deaf community, and TV culture, a national public channel. Then, we recorded and photographed these three signs (now available in: (a) https://youtu.be/jdvLueyoQfo, (b) https://youtu.be/sE7CoHEbsoM, and (c) https://youtu.be/V4GnU8qIQdY).

Since Sign Language is part of the visual - spatial linguistic modality based on body articulation that involves arms, hands, fingers, chest and face and the phonetic - phonological variations of the signs of the Brazilian Sign Language (BSL-Libras) occur based on parametric conditions including: Hand Configuration (CM), Location (LOC), Movement (MOV), Palm Orientation (OR), Manual Expressions (ENM) and Number of hands (NM), we analyzed these parameters as well as the classification of the sign, and meaning.

We also carried out a survey with deaf people $(\mathrm{n}=14)$ by presenting the videos of the signs A, B and C in a Google form questionnaire, asking about their understanding of the sign's meaning and the creation history/origin of them (Figure 1). Thus, we analyzed the word frequency of their answers by using the word cloud strategy described by Palma et al., 2018. On that purpose we used Tagul, a free online word cloud generator (https://wordart.com/create), and verified: 1) the suitability of our analysis of these signs's meaning, and 2) the risk of misinterpretation when use them.

\section{Results and Discussion}

Studies on phonetics and phonology of sign languages are quite recent (Viroja, 2019) and Stokoe (1960) was the linguistic researcher that proposed a phonological model for the analysis of American Sign Language (ASL) focusing his studies on sign language phonology.

According to Castro Junior (2011), linguistic variation in the Brazilian Sign Language can occur due to several factors, such as geographic and/or regional, but other aspects also influence how academic education and the relationship of

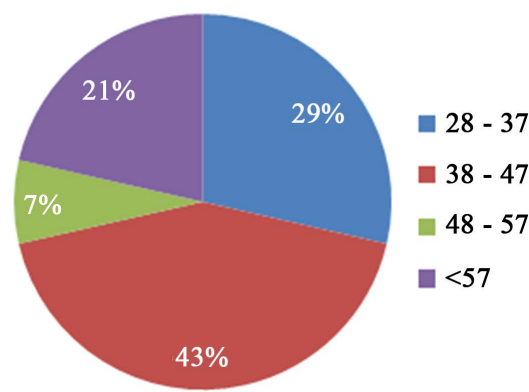

(a)

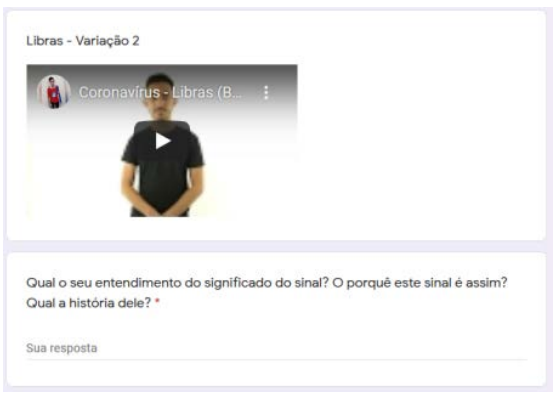

(b)

Figure 1. Survey with the deaf volunteers $(n=14)$ about their understanding of the sign's meaning and creation history/origin. (a) Age of the volunteers; (b) Google formulary with the Brazilian Sign language interpreter video of the sign B and the discursive question. 
linguistic status and minority groups to which they belong. The variation is expected between groups of different generations and the period in which the language was exposed.

Our brief linguistic analysis was performed by using the reports of Alecrim and Xavier (2017), that analyzed the variation observed in two hand configurations ("A' and S"), interchangeable in the creation of some signs. According to Xavier and Barbosa (2017), the phonological parameters presented by Stokoe (1960) considered as a support and recognition of minimal pairs, which is pairs of signs similarly specified for almost all articulatory aspects, with the exception of one of them.

Our analysis of the three Brazilian signs of coronavirus showed that they are similar when it comes to the location of the parameters, number of hands and classification (Type) (Table 1 and Figure 1) but present variation on other aspects as reported by some authors for other languages where the iconicity and arbitrary define their similarity and/or diversity (Tsay et al., 2000).

All the signs for the term coronavirus in Brazil that we analyzed are iconic, alluding to the meaning and/or infectious situation involving this virus at some level (Teixeira, 2020). In the case of sign A, adopted in China, the first movement represents the form of infection (the signal was created when coronavirus infection was believed to be due to a bat bite), while the latter represent rapid spread in the population (Figure 2). The problem with this signal is that it possibly creates the wrong fear for that bats or animals that bite (e.g., snakes) and the false impression that if the bat doesn't bite the person, there's no risk.

The second sign (B) represent the viral envelope that looks like a crown at a first glance, whereas the last and third sign (C), which was created by deaf people after advised by a biologist, represents the whole coronavirus envelope structure in a more correct message/information (Figure 2).

Table 1. Comparison of the three signs (A-C) for coronavirus from Brazil and different parameters such as sign classification (Type-Arbitrary, Iconic, Descriptive and/or Datilology), origin, meaning, Hand Configuration (CM), Location (LOC), Movement (MOV), Palm Orientation (OR), and Number of hands (NM).

\begin{tabular}{|c|c|c|c|c|c|c|c|c|}
\hline Sign & Type & Origin & Meaning & $\mathrm{CM}$ & LOC & MOV & OR & NM \\
\hline$(A)^{*}$ & Iconic & China & $\begin{array}{c}\text { Animal bite } \\
\text { and disease } \\
\text { spread }\end{array}$ & $32 / 69$ & $\begin{array}{l}\text { Neutral space } \\
\text { in front } \\
\text { of the body }\end{array}$ & $\begin{array}{c}\text { Straight } \\
\text { movement }\end{array}$ & $\begin{array}{l}\text { Palm } \\
\text { down }\end{array}$ & 2 \\
\hline$(\mathrm{B})^{\star *}$ & Iconic & France & $\begin{array}{c}\text { Virus } \\
\text { concept }\end{array}$ & $67 / 05$ & $\begin{array}{l}\text { Neutral space } \\
\text { in front } \\
\text { of the body }\end{array}$ & Semicircular & $\begin{array}{l}\text { Palm } \\
\text { forward }\end{array}$ & 2 \\
\hline$(C)^{\star \star * \star}$ & Iconic & Brazil & $\begin{array}{l}\text { Virus concept } \\
\text { built by deaf } \\
\text { people after } \\
\text { advise of a } \\
\text { biologist. }\end{array}$ & $69 / 05$ & $\begin{array}{l}\text { Neutral space } \\
\text { in front } \\
\text { of the body }\end{array}$ & Semicircular & $\begin{array}{c}\text { Palm } \\
\text { forward, } \\
\text { then left } \\
\text { and finally } \\
\text { inward }\end{array}$ & 2 \\
\hline
\end{tabular}

${ }^{*}$ Available in https://youtu.be/jdvLueyoQfo; ${ }^{* *}$ Available in https://youtu.be/sE7CoHEbsoM; ${ }^{* * *}$ Available in https://youtu.be/V4GnU8qIQdY. 


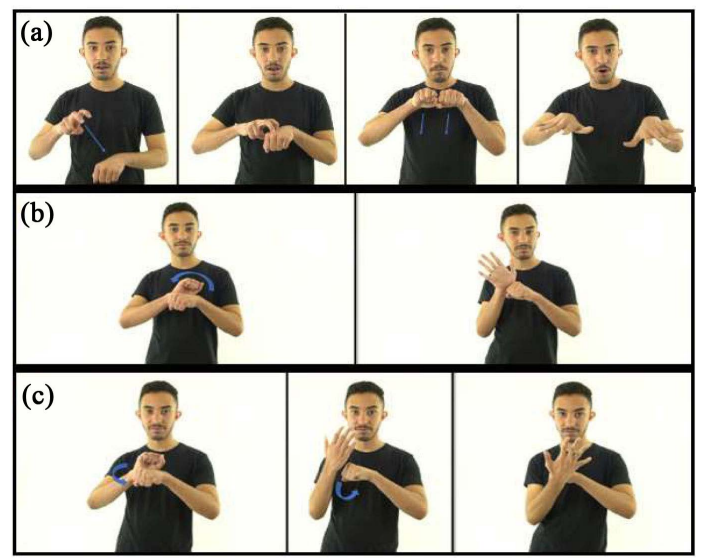

Figure 2. The three signs ((a)-(c)) for coronavirus currently in use in Brazil.

The analysis of the three signs showed that $\mathrm{B}$ and $\mathrm{C}$ use two different hand configurations (Figure 2 and Table 1), which represent the same meaning as well as Movement and Palm Orientation (Figure 2 and Table 1). This is in agreement with the literature that reported that there are some signs in BSL/Libras in which signs can be generated with different hand configurations for representing the same topic/content (Quadros, 2019).

In the analysis of the Linguistic classification of the sign $\mathrm{C}$, we note that this sign is close to a sign-term to be considered standard, as it presents all the parametric conditions that allow a registration and technical use. According to $\mathrm{Ca}$ stro Junior (2014), it is necessary to unfold the parametric conditions for the formation of infinite possibilities for the creation of the signs-term, but they must: a) follow a logic articulated by the parametric basis, and b) be based on Linguistic theories and in its various studies of effectively, for a clear understanding of the properties of parametric conditions. Historical changes in languages often take place in the vocabulary, but some changes can occur in the parametric conditions of the terms and characterize an error or a new variant, so the registration of the parametric base serves as a standard for the registration of terms in Libras.

In this work, we also evaluated the suitability of our analysis of these signs' meaning and the risk of misinterpretation when use them. For that purpose, we carried out a survey with deaf people $(\mathrm{n}=14)$ as described in the Methods section (Figure 3). Interestingly, our analysis about the risk of misinterpretation of sign A (Table 1) was confirmed when most of the words on the answers of deaf volunteers, after seeing it, involved bite and an animal (bat, dog or Pandolim), different from the other two signs (Figure 3). Even the name of the virus (coronavirus) was less expressive on sign A's cloud compared not only to the words bat and bite within, but also when compared with signs B and C. We also detected the fairness of the history about the shape of the virus on Sign B and the biologist help on the creation of sign C (Figure 3).

Importantly our data suggested that the iconicity of the sign A, which was created in the initial of the pandemic when Chinese people did not know much 

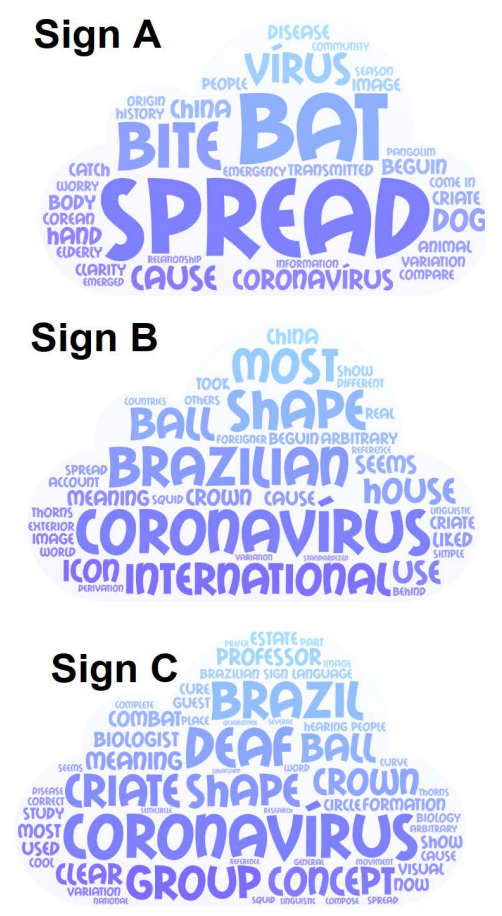

Figure 3. Analysis of the word frequency on answers of the deaf volunteers $(\mathrm{n}=14)$ about signs $\mathrm{A}, \mathrm{B}$ and $\mathrm{C}$ and their understanding of the sign's meaning, and creation history/origin.

about it, is strong enough to lead to misinterpretation on how to get infected by coronavirus. This misunderstanding is very dangerous as do not lead deaf people to adopt preventive actions against the virus but against the animal that may bite them (e.g. bat). The WHO and CDC instructed about the preventive actions and the need of all society adopting them but even in the site of these institutions, there is no access for deaf communities on their sign language version/translation (WHO, 2020 and CDC, 2020).

In the literature, some authors discussed the variability and stability in the production of signal language, including Brazilian Sign Language - Libras, and how iconic signs are less stable than arbitrary signs (Xavier \& Barbosa, 2017; Tsay et al., 2000). As we can observe, the creation of signs B and C to apparently substitute sign $\mathrm{A}$ is totally justified as they are directly related to the real agent of COVID_19, which is the coronavirus, revealing details such as shape and biologic characteristics. However, we also have to remember that the use of two or three signs is not productive as also obligate the deaf community and interpreters to know all of them in order to have or give access to every information available in Brazilian Sign Language-Libras.

\section{Final Considerations}

In announcing actions to reduce the number of deaths and to increase the quality of care for patients with COVID_19, WHO said that the integrated work of all societies of every country, is essential. Thus, on that matter, the deaf community 
should not be forgotten, and we have to work in every way, not only to fight this disease but also to improve the accessibility level of this information to this community.

It is important to note that written networks without sign language translation is not the best way to give information to the deaf community since they are presented on their second language (the written form of the country's first language, e.g. Portuguese) instead of their own first language (e.g. Brazilian Sign Language/Libras). The use of the sign language allows the deaf community to gain access to the technical language for communication whereas enables individual and collective care.

On that matter, when it comes to health threats such as coronavirus and COVID-19, it is important that WHO, together with WFD, creates unique signs during these situations. By creating signs with the correct meaning to be used worldwide by these minorities, such as suggested by us on the last Nature edition (Castro et al., 2020), this action would help on standardizing sign language for health and academic purposes all over the world.

Globalization allows users to have access to the most varied content. This action may also assure accessibility to the deaf community in their own language at the same level of the hearing people, especially when the subject is a huge public health issue, such as coronavirus and COVID-19.

\section{Acknowledgements}

We thank CNPq, FAPERJ, UFF, and CAPES for the financial support and fellowships.

\section{Conflicts of Interest}

The authors declare no conflicts of interest regarding the publication of this paper.

\section{References}

Albres, N. A. (2012). The Construction of Signals and Their Specific Mobility. In Brazilian Sign Language Libras: Linguistic and Historical Aspects (pp. 81-98). São Carlos: Editora da UFSCar.

Alecrim, E. C., \& Xavier, A. N. (2017). Description of the Phonetic Variation in Libras. In Notebooks of the Week of Letters of UFPR (pp. 41-53). Curitiba: Humanities Sector.

Castro Junior, Gláucio de. (2011). Linguistic Variation in Brazilian Sign Language-Focus on the Lexicon. 123 f. Dissertation (Master’s), University of Brasília, UNB, Brasília, DF. https://repositorio.unb.br/bitstream/10482/8859/1/2011_GA1uciodeCastroBAnior.pdf

Castro Junior, Gláucio de. (2014). Project VARLIBRAS. 159 f. Thesis (Doctorate), University of Brasília, UNB, Brasília, DF.

https://repositorio.unb.br/handle/10482/17728_GA1uciodeCastroBAnior.pdf

Castro, H. C., Ramos, A. S. L., Amorim, G., \& Ratcliffe, N. A. (2020). COVID-19: Don't Forget Deaf People. Nature, 579, 343. https://doi.org/10.1038/d41586-020-00782-2

CDC (2020). Corona vírus Disease 2019 (COVID-19). Steps to Prevent Illness. 
https://www.cdc.gov/coronavirus/2019-ncov/index.html

Du, M. (2020). Is Linguistic Organization Amodal? Some Evidence from the Sign Languages. In Series: Advances in Social Science, Education and Humanities Research from Proceedings of the International Conference on Modern Educational Technology and Innovation and Entrepreneurship (pp. 29-32s). Paris, Atlantis Press. https://doi.org/10.2991/assehr.k.200306.072

Palma, M., Santana, A., Alves, G., Merçon, T., \& Castro, H. (2018). Nursing and Biochemistry: An Evaluation Strategy Using a Basic Discipline to Present to Freshman Students Their Future Professional Environment. Creative Education, 9, 497-512. https://doi.org/10.4236/ce.2018.93035

Prietch, S. S., Pineda, I. O., Paim, P. S., Calleros, J. M. G., García, J. G., \& Resmin, R. (2019). Discussion on Image Processing for Sign Language Recognition: An Overview of the Problem Complexity. In Research and Development of New Technology (pp. 112-127). Huelva, España DR @ United Academic Journals (UA Journals).

Quadros, R. M. (2019). Libras. Linguistics for Higher Education, São Paulo: Editorial Parable.

Stokoe, W. (1960). Sign Language Structure: An Outline of the Visual Communication Systems of the American Deaf (p. 8). Studies in Linguistics: Occasional Papers, Washington DC: Gallaudet University Press.

Teixeira, V. G. (2020). Libras' Iconicity and Arbitration. http://www.filologia.org.br/vii_sinefil/COMPLETOS/A\%20iconicidade\%20e\%20arbitra riedade\%20na\%20Libras\%20-\%20VANESSA.pdf

Tsay, J., Sagara, K., \& Kikusawa, R. (2000). Arbitrary Signs Are More Stable than Iconic Signs: Evidence from Taiwan Sign Language and Japanese Sign Language. http://www.sillr.jp/ssll2019/abstract/S2_Tsay_et_al.pdf

Viroja, K. (2019). A Study of Sign Language Phonology. Journal of Humanities and Social Sciences, 30, 2562.

WHO (2020). Corona Virus Disease (COVID-19) Advice for the Public. https://www.who.int/emergencies/diseases/novel-coronavirus-2019/advice-for-public

Xavier, A. N., \& Barbosa, F. V. (2017). Variability and Stability in the Production of Libras Signals. Language Domains, 11, 983.

https://doi.org/10.14393/DL30-v11n3a2017-25 